\title{
RUNX3 as a Potential Predictor of Metastasis in Human Pancreatic Cancer
}

\author{
ERNESTO ROSSI ${ }^{1}$, CINZIA BAGALÀ ${ }^{1}$, FREDIANO INZANI ${ }^{2}$, EMANUELE LEONCINI ${ }^{3}$, \\ CHIARA BRUNELLI ${ }^{2}$, PAOLA LANZA ${ }^{2}$, MICHELE BASSO ${ }^{1}$, GIAN CARLO MATTIUCCI $^{4}$, \\ ALESSANDRA CASSANO $^{1}$, GUIDO RINDI ${ }^{2}$, CARLO BARONE $^{1}$ and GIOVANNI SCHINZARI ${ }^{1}$ \\ ${ }^{1}$ Department of Medical Oncology, Fondazione Policlinico "A.Gemelli”, Largo A. Gemelli, Rome, Italy; \\ ${ }^{2}$ Institute of Anatomic Pathology, Fondazione Policlinico "A.Gemelli", Largo A. Gemelli, Rome, Italy; \\ ${ }^{3}$ Section of Hygiene, Institute of Public Health, Fondazione Policlinico "A.Gemelli", Largo A. Gemelli, Rome, Italy; \\ ${ }^{4}$ Department of Radiation Oncology, Fondazione Policlinico "A.Gemelli", Largo A. Gemelli, Rome, Italy
}

\begin{abstract}
Background/Aim: In genetically engineered murine models of pancreatic ductal adenocarcinomas (PDAC), high levels of Runx3 increase the metastatic potential of cancer cells. In this study we evaluated the role of Runx3 in human pancreatic cancer. Materials and Methods: Runx3 was retrospectively assessed by immunohistochemistry in seventyeight tumor samples of patients who underwent surgical resection for PDCA and were followed at least for 24 months. Results: Thirty-two cases resulted completely negative for Runx3; forty-six showed highly variable expression. We established an optimal cut-off value of Runx3 in predicting distant metastasis equal to 0.04. The odds ratio (ORs) for development of distant metastases at multivariate analysis for patients having Runx3 $\geq 0.04$ was 4.26 ( $p=0.043)$ and 4.68 $(p=0.032)$ after adjusting for residual tumor and treatment, respectively; OR for development of metastases in multiple sites was 4.28 ( $p=0.025)$ for Runx $3 \geq 0.04$. Conclusion: Our results support the ability of Runx3 to contribute to the dissemination of human PDAC thus confirming the observations from murine models.
\end{abstract}

Although the majority of pancreatic cancers show an extreme tendency to disseminate, a minority of patients are characterized by a local tumor growth. The reasons for these

This article is freely accessible online.

Correspondence to: Rossi Ernesto, Department of Medical Oncology, Fondazione Policlinico "A. Gemelli" - Università Cattolica del Sacro Cuore, Largo A. Gemelli 8, Rome, Italy. Tel: +390630156318, e-mail: ernestorossi.rm@gmail.com

Key Words: RUNX3, pancreatic cancer, metastasis, surgical resection. distinct behaviors remain unclear so it is absolutely necessary to better understand the molecular mechanisms of this disease.

Transforming growth factor- $\beta$ proteins are fundamental regulators of pancreatic cell function and exert a key role in pancreatic disease and cancer development (1). After TGF $\beta$ receptor II binds to TGF $\beta$ ligands, it forms a dimer with TGF $\beta$ receptor I and transphosphorylates this receptor which activates Smad proteins. Activated Smad4 complexes can migrate from the cytoplasm to the nucleus and mediate transcription of target genes complexing with Runx3 at specific intranuclear foci (2). Human Runx3 (RUNT-related transcription factor 3 ) is a member of the RUNT family.

Runx3 was initially found to be a neurospecific transcription factor with an important role in lineage specification and homeostasis of CD8 positive T cells $(3,4)$. The role of Runx3 in tumorigenesis is not well defined; it was considered a tumor suppressor gene in some malignancies and an oncogene in others (5-8). In gastric cancer it was considered a tumor suppressor gene with a loss of Runx3 expression in 45-60\% of cases (8). The chronic infection by Helicobacter pylori can cause the inactivation of Runx3 gene leading to gastric cancer (9). In colon cancer Runx 3 is believed to have tumor suppressor properties and its nuclear expression is associated with a prolonged survival $(10,11)$. Li $\mathrm{J}$ et al. have found that Runx3 is expressed only in islet cells in normal pancreatic tissue, but moderate expression was observed in most of the pancreatic cancer cells while some tumors showed relatively strong Runx3 staining in the cytoplasm and in a considerable number of nuclei; their hypothesis was that Runx3 gene plays a role in the pathogenesis of pancreatic cancer (12). In genetically engineered murine models of pancreatic ductal adenocarcinoma, Whittle et al. recently demonstrated that high levels of Runx3 increase the migratory and metastatic 
potential of pancreatic cancer cells when Smad4 was not deleted; in cases of high Runx3 and complete loss of Smad4, both a tendency to disseminate and to grow locally was found, while low Runx3 levels were associate with a higher possibility of local growth. In order to further investigate the role of Runx3 as a factor able to induce cancer cells dissemination, they also demonstrated that high levels of Runx3 are associated, both in pancreatic cancer murine models and in human cells lines, with an elevated expression of extracellular matrix proteins, such as Osteopontin and Col6a1, which can promote the migration of cancer cells. The authors proposed that Runx 3 could be considered in pancreatic cancer both a tumor suppressor of local proliferation and a promoter of distant metastatization (13).

If the findings of the abovementioned study were confirmed in pancreatic cancer patients it would be suggested that patients with high levels of Runx3 and normal expression of Smad4 probably could benefit most from initial systemic therapy followed by resection considering the relatively lower risk for local growth, while tumors in patients with low expression of Runx3 may be resected or eventually treated with a short course of radiation prior to resection. For patients with high Runx3 expression and complete loss of Smad4, the rationale could be a short course of chemoradiation before the systemic cytotoxics. The aim of the present study was to investigate the expression of Runx3 and Smad4 in surgically resected pancreatic ductal adenocarcinoma in order to evaluate their possible role in local tumor relapse or distant dissemination; this evaluation could contribute to guide the peri-operative treatment strategy of pancreatic cancer patients.

\section{Materials and Methods}

Patients. Seventy-eight patients who underwent surgical resection from 2006 to 2014 for pancreatic adenocarcinoma were included in this retrospective analysis. All patients received surgical treatment with curative intent and they were followed at our Institution for at least 24 months. Resected tumors were staged according to the TNM system and resection margin was classified as R1 if there was microscopic evidence of neoplastic cells within $1 \mathrm{~mm}$ of the resection margin (14). Post-operative treatment, including chemotherapy based on Gemcitabine $(1000 \mathrm{mg} / \mathrm{mq}$ on days $1,8,15$ every 4 weeks for 6 cycles) or chemotherapy (Gemcitabine) plus radiotherapy (50.4 Gy to the tumor, 39.6 Gy to the nodes), was administered according to national and international guidelines (15, 16). After surgery or adjuvant treatment, patients received clinical and radiological assessments every 3-4 months until relapse. Sites of relapse were assessed through CT-scan or PET-CT. For relapsing disease, patients received cytotoxic therapy mainly including one of the most commonly used regimens, FOLFIRINOX (Fluorouracil bolus $400 \mathrm{mg} / \mathrm{mq}$ and $46-\mathrm{h}$ continuous infusion $2,400 \mathrm{mg} / \mathrm{mq}$, leucovorin $200 \mathrm{mg} / \mathrm{mq}$, irinotecan $180 \mathrm{mg} / \mathrm{mq}$, oxaliplatin $85 \mathrm{mg} / \mathrm{mq})$ every 2 weeks or Gemcitabine $(1,000 \mathrm{mg} / \mathrm{mq}$, days 1,8 , 15) and Nab-Paclitaxel $(125 \mathrm{mg} / \mathrm{mq}$, days $1,8,15)$ every 4 weeks or Gemcitabine $1,000 \mathrm{mg} / \mathrm{mq}$ and Oxaliplatin $100 \mathrm{mg} / \mathrm{mq}$ every 2 weeks, according to national and international guidelines $(15,16)$.
We considered disease free survival (DFS) as the period between surgery and relapse of disease and overall survival (OS) as period between surgery and death or the last follow-up visit.

Histological analysis. Histological revision and immunohistochemical evaluation were performed by three pathologists (G.R., F.I. and C.B.). Original slides were reviewed and one representative sample of primary tumor was chosen for immunohistochemistry investigation. Tests for Runx3 (primary antibody R3-5G4, Abcam, 1:500), Smad4 (EP618Y, Abcam, 1:300) and Ki67 (MIB1, DAKO, 1:50) were performed in all cases.

For Runx3 only nuclear immunoreactivity was considered. Normal lymphocytes, common sites of elevated Runx3, showed strong nuclear expression and were used as internal positive controls (17). Immunohistochemical expression of antigens by tumor cells was expressed in a percentage value on overall tumor cell population.

For Smad4 cytoplasmic and nuclear staining were considered. Each case was scored as "positive" when neoplastic cells showed diffuse staining comparable with the surrounding normal pancreatic parenchyma deemed as control; "negative" when neoplastic cells did not show any labeling or showed focal and weak positivity $v$. control pancreas (18).

For Ki67 three representative tumor areas, including hot spots, were analyzed at 200x and quantified; the mean percentage obtained was recorded as the Ki-67 labeling index for each tumor.

The study has been approved by the local Ethics Committee.

Statistical analysis. A descriptive analysis was conducted to show the characteristics of the 78 patients at the time of diagnosis. The optimal cut-off value of Runx 3 expression in predicting distant metastasis was determined according to the receiver-operator characteristic (ROC) analysis. The associations between distant metastasis and number of metastasis and Runx3 were assessed by estimating odds ratios (ORs) and $95 \%$ confidence intervals (CIs), obtained from logistic regression models. In the multiple regression models, confounders were included if the $p$-value was less than 0.20 or if they altered the coefficient of the Runx3 expression by more than 10 percent. The potential confounding variables considered were age, gender, stage of tumor, tumor treatment, presence of residual tumor, ki67 and Smad4. The Kaplan Meier method was also applied to further clarify the impact of Runx3 on disease free survival and overall survival. The log rank test was used to test any difference between the two groups across the study period. The Mann-Whitney two-sample statistic was used to determine the significance of the differences in Ki67 among patients with different levels of Runx3 expression. All $p$-values were based on two-sided tests. Statistical analyses were done with Stata software (StataCorp. 2015. Stata Statistical Software: Release 14. College Station, TX: StataCorp LP).

\section{Results}

Patients' characteristics. Baseline characteristics of the 78 patients (pts) included in the present study are shown in Table I. Sixty-nine patients $(88.5 \%)$ had stage I or II tumors, while 9 pts $(11.5 \%)$ had stage III tumors; sixty-three pts (81\%) had R0 resection and 15 pts $(19 \%)$ had R1 resection. Median ki67 was 20\%. Nineteen patients (24\%) did not receive post-operatory treatment while 29 pts (37\%) were treated with adjuvant chemotherapy and 30 pts $(38.5 \%)$ 
Table I. Characteristics of the 78 patients who underwent surgical resection for pancreatic adenocarcinoma.

\begin{tabular}{|c|c|c|}
\hline & $\mathrm{n}$ & $\%$ \\
\hline \multicolumn{3}{|l|}{ Age } \\
\hline Less than 60 & 17 & $21.8 \%$ \\
\hline $60-69$ & 23 & $29.5 \%$ \\
\hline 70 or more & 38 & $48.7 \%$ \\
\hline \multicolumn{3}{|l|}{ Gender } \\
\hline Male & 36 & $46.2 \%$ \\
\hline Female & 42 & $53.8 \%$ \\
\hline \multicolumn{3}{|l|}{ Stage } \\
\hline I-II & 69 & $88.5 \%$ \\
\hline III & 9 & $11.5 \%$ \\
\hline \multicolumn{3}{|l|}{ Treatment } \\
\hline None & 19 & $24.4 \%$ \\
\hline RT & 29 & $37.2 \%$ \\
\hline $\mathrm{CT}+\mathrm{RT}$ & 30 & $38.5 \%$ \\
\hline \multicolumn{3}{|l|}{ Residual tumor } \\
\hline R0 & 63 & $80.8 \%$ \\
\hline $\mathrm{R} 1$ & 15 & $19.2 \%$ \\
\hline \multicolumn{3}{|l|}{ Ki67 } \\
\hline Median (IQR) & \multicolumn{2}{|c|}{$0.20(0.15-0.43)$} \\
\hline \multicolumn{3}{|l|}{ Smad4 } \\
\hline Negative & 39 & $50.0 \%$ \\
\hline Positive & 39 & $50.0 \%$ \\
\hline \multicolumn{3}{|l|}{ Runx3 } \\
\hline Median (IQR) & \multicolumn{2}{|c|}{$0.02(0.00-0.25)$} \\
\hline Negative & 32 & $41.0 \%$ \\
\hline Positive & 46 & $59.0 \%$ \\
\hline$<0.04$ & 47 & $60.3 \%$ \\
\hline$\geq 0.04$ & 31 & $39.7 \%$ \\
\hline
\end{tabular}

Values are expressed as frequency and percentage, unless indicated otherwise. IQR: Interquartile range; CT: chemotherapy; RT: radiation therapy.
Table II. Characteristics of the 59 patients who experienced disease relapse.

\begin{tabular}{|c|c|c|c|}
\hline & $\begin{array}{l}\text { Local recurrence } \\
\qquad(\mathrm{n}=16)\end{array}$ & $\begin{array}{l}\text { Distant metastases } \\
\qquad(\mathrm{n}=43)\end{array}$ & $\begin{array}{l}\text { Total } \\
(\mathrm{n}=59)\end{array}$ \\
\hline \multicolumn{4}{|l|}{ Age } \\
\hline Less than 60 & $5(31.3 \%)$ & $8(18.6 \%)$ & $13(22.0 \%)$ \\
\hline $60-69$ & $5(31.3 \%)$ & $12(27.9 \%)$ & $17(28.8 \%)$ \\
\hline 70 or more & $6(37.4 \%)$ & $23(53.5 \%)$ & $29(49.2 \%)$ \\
\hline \multicolumn{4}{|l|}{ Gender } \\
\hline Male & $8(50.0 \%)$ & $19(44.2 \%)$ & $27(45.8 \%)$ \\
\hline Female & $8(50.0 \%)$ & $24(55.8 \%)$ & $32(54.2 \%)$ \\
\hline \multicolumn{4}{|l|}{ Stage } \\
\hline I-II & $15(93.7 \%)$ & $36(83.7 \%)$ & $51(86.4 \%)$ \\
\hline III & $1(6.3 \%)$ & $7(16.3 \%)$ & $8(13.6 \%)$ \\
\hline \multicolumn{4}{|l|}{ Treatment } \\
\hline None & $2(12.5 \%)$ & $10(23.3 \%)$ & $12(20.3 \%)$ \\
\hline $\mathrm{CT}$ & $6(37.5 \%)$ & $19(44.2 \%)$ & $25(42.4 \%)$ \\
\hline $\mathrm{CT}+\mathrm{RT}$ & $8(50 \%)$ & $14(32.6 \%)$ & $22(37.3 \%)$ \\
\hline \multicolumn{4}{|l|}{ Residual tumor } \\
\hline R0 & $10(62.5 \%)$ & $34(79.1 \%)$ & $44(74.6 \%)$ \\
\hline $\mathrm{R} 1$ & $6(37.5 \%)$ & $9(20.9 \%)$ & $15(25.4 \%)$ \\
\hline \multicolumn{4}{|l|}{ Ki67 } \\
\hline Median (IQR) & 0.28 & 0.20 & 0.20 \\
\hline & {$[0.13-0.47]$} & [0.16-0.43] & [0.15-0.43] \\
\hline \multicolumn{4}{|l|}{ Smad4 } \\
\hline Negative & $6(37.5 \%)$ & $23(53.5 \%)$ & $29(49.2 \%)$ \\
\hline Positive & $10(62.5 \%)$ & $20(46.5 \%)$ & $30(50.8 \%)$ \\
\hline \multicolumn{4}{|l|}{ Runx3 } \\
\hline Median (IQR) & 0.01 & 0.04 & 0.02 \\
\hline & {$[0.0-0.14]$} & {$[0.00-0.30]$} & [0.00-0.25] \\
\hline Negative & $7(43.7 \%)$ & $13(30.2 \%)$ & $20(33.9 \%)$ \\
\hline Positive & $9(56.3 \%)$ & $30(69.8 \%)$ & $39(66.1 \%)$ \\
\hline$<0.04$ & $12(75.0 \%)$ & $21(48.8 \%)$ & $33(55.9 \%)$ \\
\hline$\geq 0.04$ & $4(25.0 \%)$ & $22(51.2 \%)$ & $26(44.1 \%)$ \\
\hline
\end{tabular}

Values are expressed as frequency and percentage, unless indicated otherwise. IQR: Interquartile range; CT: chemotherapy; RT: radiation therapy.

received both cytotoxic and radiation adjuvant treatment according to risk factors of relapse. During follow-up, 59 patients $(75 \%)$ experienced disease relapse; the demographics and clinical features of these patients are summarized in Table II. Local recurrence and distant metastases were observed in 16 (27\%) and 43 (73\%) patients, respectively; in the metastatic group we included five patients who presented both local relapse and distant metastases. In the metastatic group, 9 pts $(20,9 \%)$ had a R1 resection, while in the local relapse group, 6 pts $(37,5 \%)$ had R1 resection. Median ki67 for patients with local relapse was $28 \%$, and it was $20 \%$ for patients with distant metastases.

Runx3 analysis. Thirty-two (41\%) cases resulted completely negative for Runx3 (Table II); the other cases $(n=46,59 \%)$ showed highly variable expression of Runx3 from rare and scattered positive cells to diffuse positivity (Figures 1-3); median expression of Runx 3 was $2 \%$. The optimal cut-off value of Runx3 in predicting distant metastasis was 0.04 by ROC analysis, with sensitivity and specificity of $51 \%(95 \% \mathrm{CI}=36 \%$ $67 \%)$ and $75 \%(95 \% \mathrm{CI}=48 \%-93 \%)$, respectively. The expression of Runx3 was $\geq 0.04$ in $26 / 59$ cases ( $44.1 \%$ ). Patients having more than one site of disease and Runx $3 \geq 0.04$ were 22/59 (37.3\%).

At univariate analysis, the odd ratio (OR) for development of distant metastases was 3.14 (95\% CI=0.87-11.30, $p=0.079)$ for patients having Runx3 expression levels higher than or equal to 0.04 (Table III). However, at multivariate analysis the OR was $4.26(95 \% \mathrm{CI}=1.05-17.26, p=0.043)$ and 4.68 (95\% CI $=1.14-19.10, p=0.032)$ after adjusting for residual tumor and tumor treatment, respectively (Table III). With regard to the number of sites of disease, the OR for development of metastases in multiple sites was 4.28 (95\% CI=1.20-15.29, $p=0.025$ ) for Runx 3 expression levels higher than or equal to 
Table III. Odds ratio (ORs) and 95\% Confidence Intervals (CIs) for distant metastases and multiple sites of metastases, among 59 patients who experienced disease relapse according to Smad4, Runx3 and selected variables.

\begin{tabular}{|c|c|c|c|c|c|c|c|c|c|c|c|c|}
\hline & \multicolumn{6}{|c|}{ Local recurrence/distant metastasis } & \multicolumn{6}{|c|}{$\begin{array}{l}\text { Local recurrence or one site of metastasis/ } \\
\text { more than one site of metastasis }\end{array}$} \\
\hline & $\underset{(95 \% \mathrm{CI})}{\mathrm{OR}}$ & $p$-Value & $\begin{array}{c}\text { OR } \\
(95 \% \mathrm{CI})^{(\S)(a)}\end{array}$ & $p$-Value & $\frac{\mathrm{OR}}{(95 \% \mathrm{CI})^{(\S)(\mathrm{b})}}$ & $p$-Value & $\underset{(95 \% \mathrm{CI})}{\mathrm{OR}} p$ & $p$-Value & $\begin{array}{c}\text { OR } \\
(95 \% \mathrm{CI})^{(\S)(\mathrm{c})}\end{array}$ & $p$-Value & $\begin{array}{c}\text { OR } \\
(95 \% \mathrm{CI})^{(\S)(\mathrm{d})}\end{array}$ & $p$-Value \\
\hline \multicolumn{13}{|l|}{ Age } \\
\hline$<70$ & 1,00 & 0,278 & 1,00 & 0,203 & 1,00 & 0,324 & 1,00 & 0,094 & 1,00 & --- & 1,00 & 0,054 \\
\hline 70 or more & $\begin{array}{c}1.92 \\
(0.59-6.21)\end{array}$ & & $\begin{array}{c}2.22 \\
(0.65-7.55)\end{array}$ & & $\begin{array}{c}1.96 \\
(0.51-7.48)\end{array}$ & & $\begin{array}{c}2.70 \\
(0.84-8.66)\end{array}$ & & --- & & $\begin{array}{c}3.38 \\
(0.98-11.63)\end{array}$ & \\
\hline \multicolumn{13}{|l|}{ Gender } \\
\hline $\begin{array}{l}\text { Male } \\
\text { Female }\end{array}$ & $\begin{array}{c}1,00 \\
1.26 \\
(0.40-3.99)\end{array}$ & 0,691 & $\begin{array}{c}1,00 \\
1.57 \\
(0.46-5.30)\end{array}$ & 0,471 & $\begin{array}{c}1,00 \\
1.21 \\
(0.37-3.88)\end{array}$ & 0,753 & $\begin{array}{c}1,00 \\
0.98 \\
(0.32-2.99)\end{array}$ & 0,969 & $\begin{array}{c}1,00 \\
0.98 \\
(0.31-3.08)\end{array}$ & 0,968 & $\begin{array}{c}1,00 \\
1.07 \\
(0.34-3.38)\end{array}$ & 0,907 \\
\hline \multicolumn{13}{|l|}{ Stage } \\
\hline $\begin{array}{l}\text { I-II } \\
\text { III }\end{array}$ & $\begin{array}{c}1,00 \\
2.92 \\
(0.33-25.80)\end{array}$ & 0,336 & $\begin{array}{c}1,00 \\
4.22 \\
(0.43-41.35)\end{array}$ & 0,216 & $\begin{array}{c}1,00 \\
3.12 \\
(0.34-28.86)\end{array}$ & 0,317 & $\begin{array}{c}1,00 \\
3.61 \\
(0.41-31.76)\end{array}$ & 0,248 & $\begin{array}{c}1,00 \\
4.46 \\
(0.48-41.12)\end{array}$ & 0,187 & $\begin{array}{c}1,00 \\
3.69 \\
(0.41-33.40)\end{array}$ & 0,245 \\
\hline \multicolumn{13}{|c|}{ Treatment } \\
\hline None & 1,00 & & 1,00 & & 1,00 & & 1,00 & & 1,00 & & 1,00 & \\
\hline $\mathrm{CT}$ & $\begin{array}{c}0.63 \\
(0.11-3.73)\end{array}$ & 0,614 & $\begin{array}{c}0.69 \\
(0.11-4.19)\end{array}$ & 0,690 & --- & --- & $\begin{array}{c}0.81 \\
(0.17-3.91)\end{array}$ & 0,793 & $\begin{array}{c}1.80 \\
(0.28-11.74)\end{array}$ & 0,537 & $\begin{array}{c}0.74 \\
(0.15-3.72)\end{array}$ & 0,718 \\
\hline $\mathrm{CT}+\mathrm{RT}$ & $\begin{array}{c}0.35 \\
(0.06-2.01)\end{array}$ & 0,239 & $\begin{array}{c}0.37 \\
(0.06-2.19)\end{array}$ & 0,276 & --- & --- & $\begin{array}{c}0.58 \\
(0.12-2.80)\end{array}$ & 0,501 & $\begin{array}{c}0.99 \\
(0.18-5.61)\end{array}$ & 0,994 & $\begin{array}{c}0.53 \\
(0.11-2.63)\end{array}$ & 0,435 \\
\hline \multicolumn{13}{|l|}{$\begin{array}{l}\text { Residual } \\
\text { tumor }\end{array}$} \\
\hline R0 & 1,00 & 0,200 & 1,00 & --- & 1,00 & 0,225 & 1,00 & 0,664 & 1,00 & 0,455 & 1,00 & 0,729 \\
\hline $\mathrm{R} 1$ & $\begin{array}{c}0.44 \\
(0.13-1.54)\end{array}$ & & --- & & $\begin{array}{c}0.45 \\
(0.13-1.62)\end{array}$ & & $\begin{array}{c}0.75 \\
(0.21-2.69)\end{array}$ & & $\begin{array}{c}0.60 \\
(0.16-2.30)\end{array}$ & & $\begin{array}{c}0.79 \\
(0.22-2.91)\end{array}$ & \\
\hline Ki67 & $\begin{array}{c}0.31 \\
(0.02-6.48)\end{array}$ & 0,454 & $\begin{array}{c}0.39 \\
(0.02-8.51)\end{array}$ & 0,552 & $\begin{array}{c}0.42 \\
(0.02-9.91)\end{array}$ & 0,590 & $\begin{array}{c}0.32 \\
(0.02-6.06)\end{array}$ & 0,448 & $\begin{array}{c}0.24 \\
(0.01-4.96)\end{array}$ & 0,359 & $\begin{array}{c}0.41 \\
(0.02-8.34)\end{array}$ & 0,561 \\
\hline \multicolumn{13}{|l|}{ Smad4 } \\
\hline Negative & 1,00 & 0,278 & 1,00 & 0,288 & 1,00 & 0,248 & 1,00 & 0,131 & 1,00 & 0,074 & 1,00 & --- \\
\hline Positive & $\begin{array}{c}0.52 \\
(0.16-1.69)\end{array}$ & & $\begin{array}{c}0.52 \\
(0.16-1.73)\end{array}$ & & $\begin{array}{c}0.49 \\
(0.15-1.64)\end{array}$ & & $\begin{array}{c}0.41 \\
(0.13-1.31)\end{array}$ & & $\begin{array}{c}0.32 \\
(0.09-1.11)\end{array}$ & & --- & \\
\hline \multicolumn{13}{|l|}{ Runx3 } \\
\hline $\begin{array}{l}<0.04 \\
\geq 0.04\end{array}$ & $\begin{array}{c}1,00 \\
3.14 \\
(0.87-11.30)\end{array}$ & 0,079 & $\begin{array}{c}1,00 \\
4.26 \\
(1.05-17.26)\end{array}$ & 0,043 & $\begin{array}{c}1,00 \\
4.68 \\
(1.14-19.10)\end{array}$ & 0,032 & $\begin{array}{c}1,00 \\
4.28 \\
(1.20-15.29)\end{array}$ & 0,025 & $\begin{array}{c}1,00 \\
3.98 \\
(1.09-14.55)\end{array}$ & 0,036 & $\begin{array}{c}1,00 \\
3.76 \\
(1.03-13.79)\end{array}$ & 0,046 \\
\hline
\end{tabular}

CT: Chemotherapy; RT: radiation therapy. (§) Estimated from multiple logistic regression models adjusted for: (a) residual tumor, (b) treatment, (c) age, (d) Smad4.

0.04. In the multivariate analysis, after adjusting for age, the $\mathrm{OR}$ was $3.98(95 \% \mathrm{CI}=1.09-14.55, p=0.036)$ and after adjusting for Smad4, the OR was $3.76(95 \% \mathrm{CI}=1.03-13.79, p=0.046$, Table III). The frequency of recurrence (both local or distant sites) in 31 patients with Runx $3 \geq 0.04$ was $83.9 \%(26 / 31)$ and that in 47 cases with Runx $<0.04$ was $70.2 \%$ (33/47). However, KaplanMeier curves revealed no significant association between Runx3 expression levels and disease-free survival $(p=0.684)$ or overall survival $(p=0.305)$. No association was found between Runx3 expression and Ki67 ( $p=0.894)$.
Smad4 analysis. Smad4 resulted positive in $39(50 \%)$ of all 78 patients and in $30(50.8 \%)$ among the 59 patients with disease relapse at local or distant sites (Table II). At univariate analysis, the OR for the development of distant metastases vs. local recurrence for positive Smad4 was $0.52(95 \% \mathrm{CI}=0.16-1.69, p=0.27)$; in the multivariate analysis OR for positive $\mathrm{Smad} 4$ was 0.52 (95\%CI=0.16$1.72, p=0.28)$ after adjusting for residual tumor and 0.49 $(95 \% \mathrm{CI}=0.15-1.64, p=0.24)$ after adjusting for treatment (Table III). 


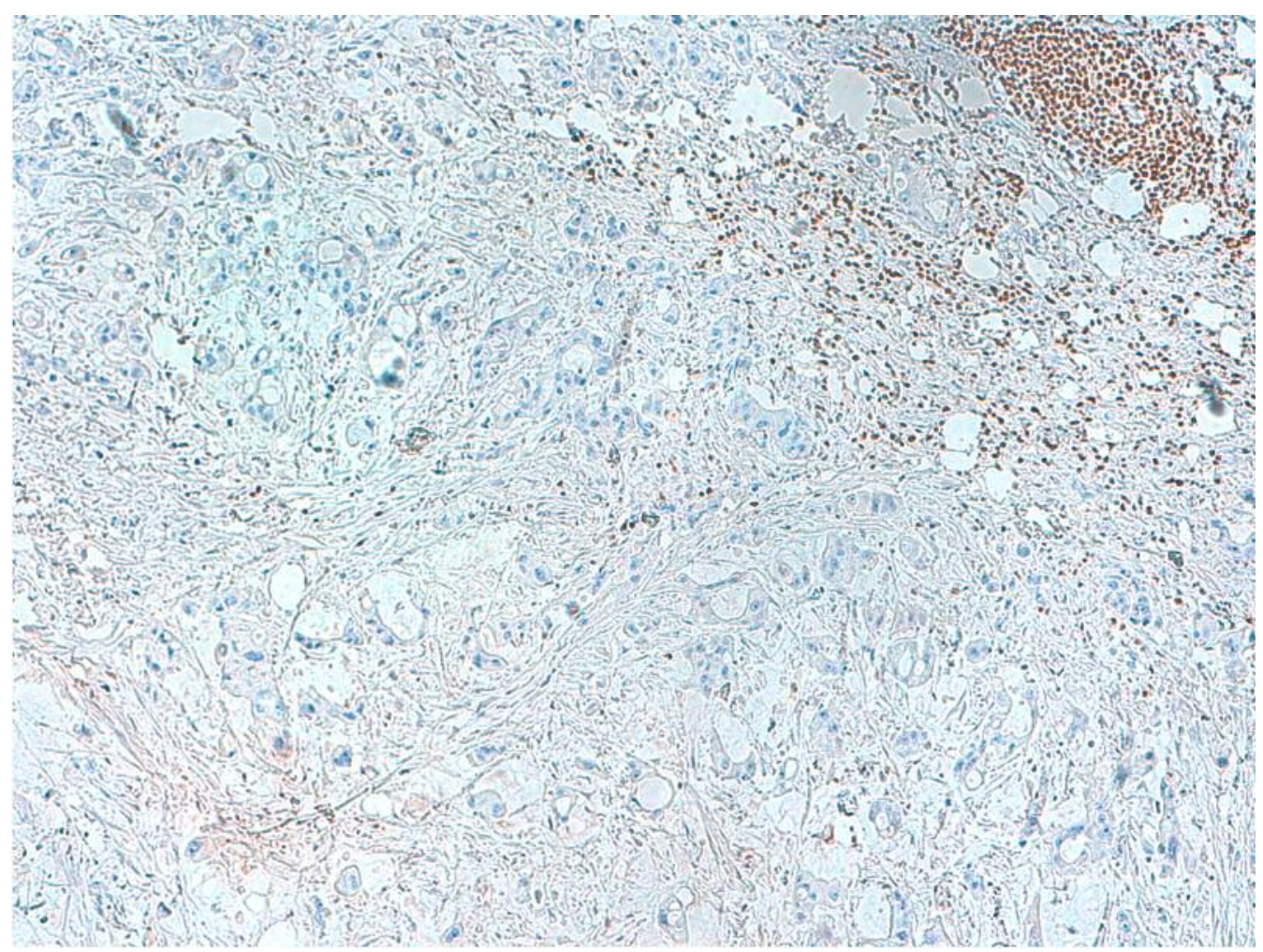

Figure 1. No Runx3 expression in cancer cells; positive control in normal lymphocytes.

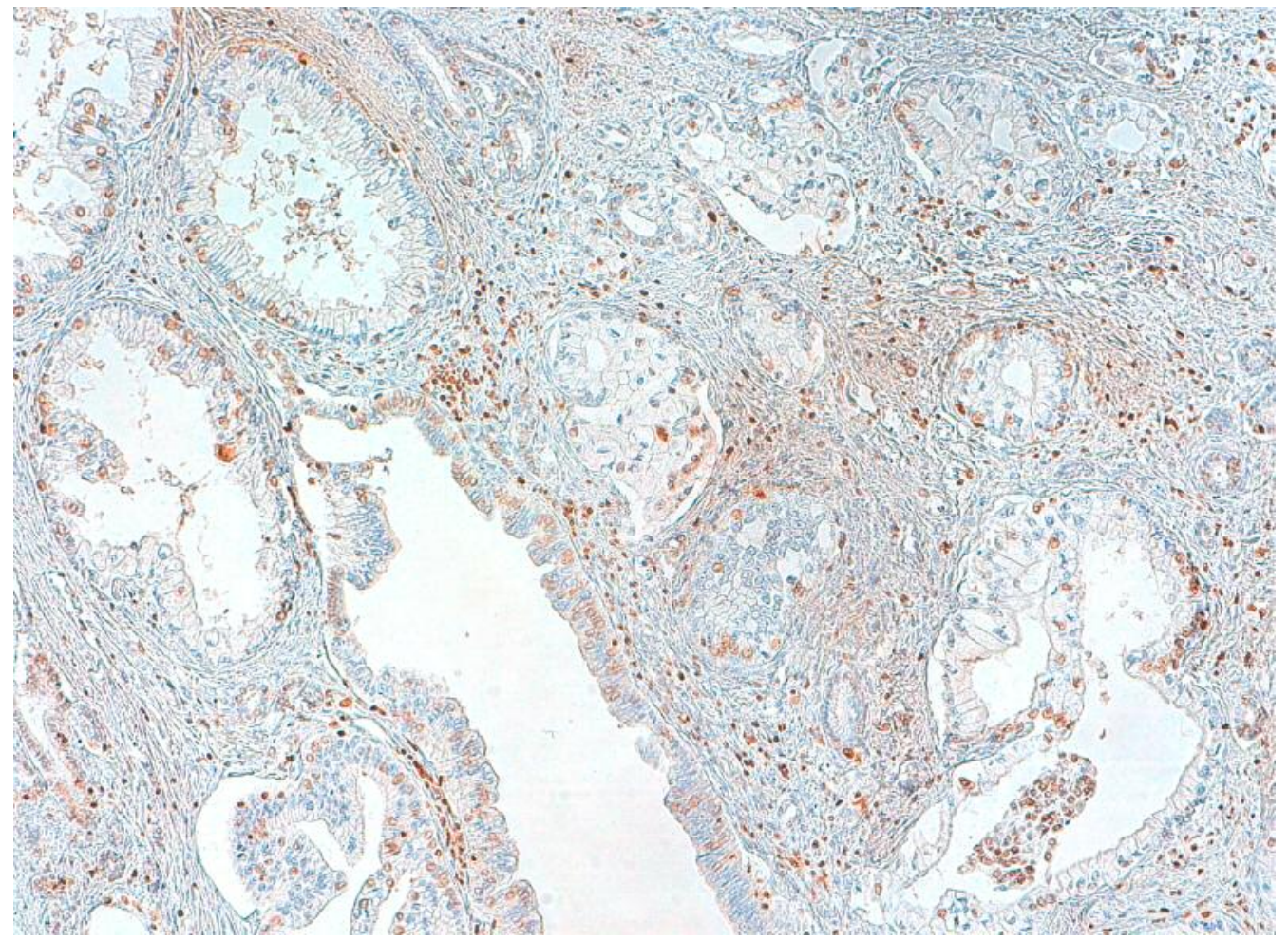

Figure 2. Cancer cells with partial expression of Runx3. 


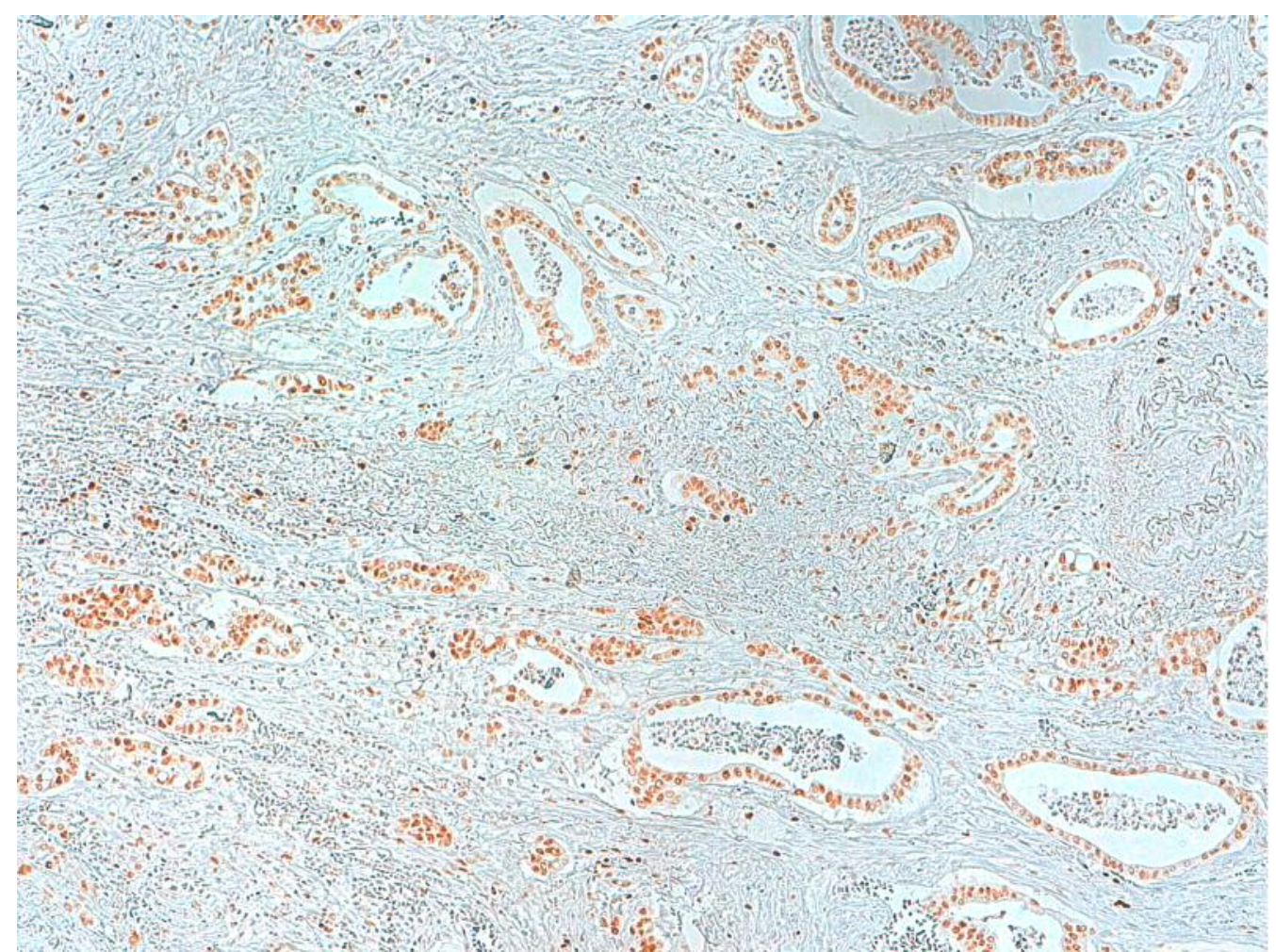

Figure 3. Diffuse nuclear immunoexpression of Runx3 in neoplastic glands.

\section{Discussion}

In the present study, we investigated Runx3 expression in ductal pancreatic carcinoma and the ability of this nuclear factor to define the tendency of tumor to grow locally or to disseminate in relation to Smad4 expression. For this purpose, we evaluated the modality of relapse -local relapse or distant metastases- of pancreatic cancer patients who underwent surgical resection.

Immunohistochemical tests for Runx 3 did not reveal any expression in normal components of pancreatic parenchyma present in the samples including ducts, islets and acini. These data are in contrast with some previous papers, since Li et al. found Runx 3 expression only in islet cells in normal pancreatic tissue and increased expression in a third of cancer tissues where it was detected both in islet and in cancer cells. Noteworthy, Li et al. observed Runx3 immunoreactivity mainly in the cytoplasm of neoplastic cells, although nuclear staining was detected in a considerable number of tumor cells. The Authors concluded that it is currently not known whether the cytoplasmic localization of Runx 3 has any functional consequences (12). These observations differ from our findings since we observed only nuclear immunoreactivity of Runx3 confirming the results by Whittle et al.; in particular normal lymphocytes, common sites of elevated Runx3, both in tumor mass and in extratumoral tissues, including peripancreatic lymph-nodes, showed strong nuclear expression which resulted in a useful internal positive control in all cases $(13,17)$. Cytoplasmic staining was observed in mucin of goblet cells present in the normal duodenal epithelium and in some neoplastic glands, but this expression was disregarded in our study. Among tumors, 32 cases resulted completely negative for Runx3; the others showed highly variable expression of Runx3 from rare and scattered positive cells to diffuse positivity. Considering this variety of expression and the poor data concerning the evaluation of immunohistochemical test for Runx3 in human pancreatic cancer, we established an optimal cut-off value of Runx3 at 0.04 .

When we compared in univariate analysis Runx3 expression levels higher than or equal to 0.04 with those lower than 0.04 , the OR for the development of distant metastases versus local relapse was not statistically significant whereas in the multivariate analysis after adjusting separately for residual tumor and post-operative treatment, the results were statistically significant. Similarly to the data by Whittle et al. in murine models, our results 
seem to confirm the ability of high levels of Runx3 to predict distant metastases in human pancreatic cancer when we consider factors able to influence the tendency of the tumor to grow locally or to disseminate, such as resection margin status and post-operative treatment. This is the first study reporting these results since Whittle et al. tried to correlate human Runx3 transcript levels with relapse site but they did not find any correlation; the Authors considered this result unsurprising because the analysis was disturbed by inflammatory cells with high baseline Runx3 levels included in the samples. Therefore, in order to support the potential role of Runx 3 to facilitate the dissemination to distant sites, we correlated Runx3 with the number of relapse sites (one $v s$. more), finding a statistical significant result. In contrast with the findings showed by Whittle et al. who demonstrated a higher proliferation rate of tumors with low levels of Runx3, we did not find any correlation between Ki67 and Runx3 expression and this could suggest that Runx3 is not involved in cancer cell proliferation but it has a specific role in stimulating tumor migration and invasiveness. This assumption is supported by the evidence that some genes in the extracellular matrix profile, such as COL6Al and osteopontin, were under Runx3 control (13).

Our results seem to support the ability of Runx3 to contribute to the dissemination of human pancreatic cancer similarly to the observations in murine models whereas it appears less probable that it influences local growth.

In our study, we observed loss of Smad4 expression in $50 \%$ of our pancreatic cancer patients and this result is in agreement with previous data reported in the specific literature; we did not find any correlation between deletion of Smad4 and Runx3 overexpression or between loss of Smad4 and metastatic relapse. Among patients relapsed and expressing Runx $3 \geq 0.04$, when we correlated Runx $3 \geq 0.04$ with the number of relapse sites adjusting for Smad4, the result was statistically significant. This result could suggest that Runx3 is not only under control of Smad4 and in fact also p53 can influence Runx3 expression promoting protein degradation; furthermore, Runx3 is able to bind other cofactors in addition to Smad, such as ETS, histone acetyltransferases and C/EBP (19). Although mutation of Smad4 occurs late during tumorigenesis of pancreatic cancer, this event may not influence the capacity of tumor to metastatize, other factors are involved in tumor dissemination and Runx 3 could be one of them.

Finally, in our study we did not observe a statistically significant correlation between Runx 3 overexpression and DFS or OS. These results could be attributed to the heterogeneity of the study population due to age, stage, postoperative treatments, residual disease and also to the limited number of patients included in the analysis.

Based on these findings we can hypothesize a specific ability of Runx3 to induce dissemination of human pancreatic cancer likely in association with other biological factors. Consequently, high levels of Runx3 in pancreatic cancer biopsies could allow to select patients who could benefit by chemotherapy treatment before pancreatic resection because their clinical early stage could be actually micrometastatic stage IV tumors. Prospective clinical trials are needed to confirm our observation in order to better address perioperative treatments of pancreatic cancer patients.

\section{Conflicts of Interest}

There are no conflicts of interest to declare.

\section{References}

1 Ito T, Shimada Y, Hashimoto Y, Kaganoi J, Kan T, Watanabe G, Murakami Y and Imamura M: Involvement of TSLC1 in progression of esophageal squamous cell carcinoma. Cancer Res 63: 6320-6326, 2003.

2 Zaidi SK, Sullivan AJ, Van Wijnen AJ, Stein JL, Stein GS and Lian JB: Integration of Runx3 and Smad regulatory signals at transcriptionally active subnuclear sites. Proc Natl. Acad. Sci USA 99: 8048-8053, 2002.

3 Levanon D, Beltoun D, Harris-Cerruti C, Woolf E, Negreanu V, Eilam R, Bernstein Y, Goldenberg D, Xiao C, Fliegauf M, Kremer E, Otto F, Brenner O, Lev-Tov A and Groner Y: The Runx3 transcription factor regulates development and survival of TrkC dorsal root ganglia neurons. EMBO J 21: 3454-3463, 2002.

4 Taniuchi I, Osato M, Egawa T, Sunshine MJ, Bae SC, Komori T, Ito Y and Littman DR: Differential requirements for Runx proteins in CD4 repression and epigenetic silencing during $\mathrm{T}$ lymphocyte development. Cell 111: 621-33, 2002

5 Ito K, Inoue KI, Bae SC and Ito Y: Runx3 expression in gastrointestinal tract epithelium: resolving the controversy. Oncogene 28: 1379-1384, 2009.

6 Levanon D, Brenner O, Negreanu V, Bettoun D, Woolf E, Eliam R, Lotem J, Gat U, Otto F, Speck N and Groner Y: Spatial and temporal expression pattern of Runx3 (Aml2) and Runx1 (Aml1) indicates non redundant functions during mouse embryogenesis. Mech Dev 109: 113-124, 2001.

7 Levanon D, Bernstein Y, Negreanu V, Bone KR, Pozner A, Eliam R, Lotem J, Brenner O and Groner Y: Absence of runx3 expression in normal gastrointestinal epithelium calls into question its tumour suppressor function. EMBO Mol Med 3: 593-604, 2011.

8 Li QL, Ito K, Sakakulra C, Fukamachi H, Inoue Ki, Chi XZ, Lee CW, Han SB, Kim HM, Kim WJ, Yamamoto H, Yamashita N, Yano $\mathrm{T}$, Ikeda $\mathrm{T}$, Itohara $\mathrm{S}$, Inazawa $\mathrm{J}$, Abe $\mathrm{T}$, Hagiwara $\mathrm{A}$, Yamagishi H, Ooe A, Kaneda A, Sugimura T, Ushijima T, Bae SC and Ito Y: Causal relationship between the loss of RUNX3 expression and gastric cancer. Cell 109: 113-124, 2002.

9 Ito K: RUNX3 in oncogenic and anti-oncogenic signaling in gastrointestinal cancers. J Cell Biochem 112: 1243-1249, 2011.

10 Peng Z, Tang H, Wang X, Zhou C, Fan J, Wang L, Jia Z, Li Q, Le $\mathrm{X}$, Wei D and Xie K: Inhibition of the growth and metastasis of human colon cancer by restoration of RUNX3 expression in cancer cells. Int J Oncol 33: 979-984, 2008. 
11 Soong R, Shah N, Peh BK, Chong PY, Ng SS, Zeps N, Joseph D, Salto-Tellez M, Iacopetta B and Ito Y: The expression of RUNX3 in colorectal cancer is associated with disease stage and patient outcome. Br J Cancer 100: 676-679, 2009.

12 Li J, Kleef J, Guweidhi I, Esposito I, Berberat PO, Giese T, Buchler MW and Friess H: RUNX3 expression in primary and metastatic pancreatic cancer. J Clin Patol 57: 294-299, 2004.

13 Whittle CM, Izeradjene K, Rani PG, Feng L, Carlson MA, Del Giorno KE, Wood LD, Goggins M, Hruban RH, Chang AE, Calses P, Thorson SM and Hingorni SR: RUNX3 controls a metastatic switch in pancreatic ductal adenocarcinoma. Cell 161: 1345-1360, 2015.

14 Campbell F, Smith R, Whelan P, Sutton R, Raraty M, Neoptolemos JP and Ghaneh P: Classification of R1 resections for pancreatic cancer: the prognostic relevance of tumour involvement within $1 \mathrm{~mm}$ of a resection margin. Histopathology 55: 277-283, 2009

15 Ducreux M, Sa Cuhna A, Caramella C, Hollebecque A, Burtin P, Goeré D, Seufferlein T, Haustermans k, Van Laethem JL, Conroy T, Aenold D Cancer of the Pancreas: ESMO clinical practise guidelines. Ann Oncol suppl 5: v56-v68, 2015.
16 NCCN Clinical Practice Guidelines for Pancreatic Cancer, Version I.2016

17 Yarmus M, Woolf E, Bernstein Y, Fainaru O, Negreanu V, Levanon D and Groner Y: Groucho/Transducine-like Enhancerof-split (TLE)-dependent and -indipendent transcriptional regulation by Runx3. Proc Natl Acad Sci USA 103: 7384-7389, 2006.

18 Wilentz RE, Su GH, Dai JL, Sparks AB, Argani P, Sohn TA, Yeo CJ, Kern SE and Hruban RH: Immunoistochemical labeling for Dpc4 mirrors genetic status in pancreatic adenocarcinomas: a new marker of DCP4 inactivation. Am J Pathol 156: 37-43, 2000.

19 Durst KL and Hierbert SW: Role of RUNX family members in transcriptional repression and gene silencing. Oncogene 2: 42204224, 2004.
Received July 3, 2017

Revised July 19, 2017

Accepted July 24, 2017 